casualty department for long periods while different doctors $x$ rayed different parts of their anatomy without relieving pain or correcting shock. All resuscitation was taken over by the medical divison, and treatment was administered using standardised methods. ${ }^{12}$ As the casualty officers constituted a rapidly changing population the onus of responsibility for recognising severe injuries and alerting the intensive care specialist fell on the nursing staff, many of whom had undergone the English Nursing Board intensive care course. To facilitate immediate resuscitation a series of algorithms was constructed and displayed prominently in the casualty department.

The second hospital in our district is much smaller ( 300 beds) and has a correspondingly smaller resident staff. Our survey had shown even greater deficiencies at this hospital with an absence of the necessary skilled staff. The setting up of a trauma team in a hospital of this size was impracticable. An alternative solution was developed, which required all prospective casualty officers first to rotate through the medical department, where they were taught to recognise severe injuries and institute treatment.

A R Luksza

Intensive Care Unit and Clinical Research

Laboratory,

Whiston Hospital,

1 Jones ES, ed. Intensive care. Lancaster: MTP Press, 1982 .
Btoddart JC. Trauma and the anaesthetist. London:
Tindall, 1984.

SIR,-We congratulate Mr J D Spencer on his enthusiasm in organising the trauma team to fill a gap in the care of the seriously injured which existed in his hospital. However, we would question whether this is the best way to care for such patients in every hospital. In six months the trauma team cared for 15 patients. Assuming that the registrars are on duty for the trauma team one day in three, each registrar would see five patients in the six months. In most district general hospitals the registrars rotate every six or 12 months, so the experience that they accumulate must be rather limited. Also these registrars, although experienced in their own specialty, may have had little specific training in dealing with severe injury.

We agree that the reception of severely ill patients should not be left to a single junior in the accident department. Many district hospitals in Britain now have accident and emergency consultants, however, and teaching centres have senior registrars training in accident and emergency. Part of this training is directed to the immediate care and assessment of the multiply injured, and most of these doctors will already have had considerable experience of dealing with such problems.

Our opinion is that there should be a single experienced person in charge of these difficult injuries, and such a person should be able quickly to assess the patient, carry out resuscitation, decide treatment priorities, and ask for specialist help as required. This person should be a person with formal training in accident and emergency.

D Ferguson

D EDBROOKE

J WARDROPE

A Courtney Crosby

Accident and Bmergency Department,

Royal Hallamshire Hospital,

Sheffield S10 2JF
SIR,-However stimulating may be the concept of a trauma team proposed by Mr J D Spencer, the suggestion that each department should produce a second on call list of registrars to cover normal working hours or to substitute at night or weekends for other experienced junior staff until the surgical and orthopaedic registrars are free is totally unrealistic. For those of us who work outside the Thames Regions, where junior staffing levels consistently remain $10-20 \%$ below the national average, and face the prospect of staffing the first line accident, trauma, and orthopaedic services in our new district general hospitals without any registrar cover whatsoever such a proposal might arouse more than just general interest.

While consultant and junior staff working in some departments may be able to afford the luxury and time of writing articles for the British Medical fournal and taking part in a plethora of different teams, others are desperately struggling for permission to employ any experienced hospital junior staff at all. Let us hope that members of the Central Manpower Committee, the DHSS, and the newly formed joint planning advisory committee will sit up and take note of the real implications of such articles and, furthermore, go on to make firm recommendations about the redistribution of junior posts between regions which will boost morale and improve patient care in those areas of the service where it is needed most.

JACKy Chambers

West Midlands Regional

Birmingham B16 9PA

\section{Diagnosis by postmortem blood} sampling

SIR,-The report of Drs $S$ Leadbeatter and D Stansbie (15 December, p 1656) of a case in which the postmortem diagnosis of familial hypercholesterolaemia had profound implications prompts me to report another case in which postmortem blood sampling led to a diagnosis with important implications for the relatives and others.

A 19 year old man was brought to the casualty department, Southend General Hospital, with cardiorespiratory arrest having collapsed at home at 0550 . He had had a bad cold with a sore throa for four days and on the previous evening had complained of vomiting, diarrhoea, and extreme malaise. At midnight his parents had noticed a large bruise on his left hip and a mottled rash on his face and upper trunk. His parents had been woken by the patient groaning, and he suffered a cardiorespiratory arrest shortly after the arrival of the general practitioner and the ambulance. Cardiopulmonary resuscitation was performed during the journey to hospital and was continued in the casualty department. Sinus rhythm was induced for a short period, but cyanosis was not reversed, and there was no spontaneous respiration. Irreversible asystole followed, and resuscitation was abandoned after a total of $\mathbf{4 0}$ minutes.

Because of the purpuric rash present over the upper part of the body and the history of upper respiratory tract infection leading to rapid demise and death a diagnosis of meningococcal septicaemia was considered. A postmortem blood culture sample was taken using an intracardiac needle and subsequently grew Neisseria menin gitidis group B. Postmortem examination showed that the brain was intensely congested and the adrenal glands showed intense haemorrhage.

The rapid diagnosis of the specific pathogen causing this overwhelming iilness-namely the meningococcus-allowed prompt prophylaxis to be administered to all the contacts, particularly the patient's parents and all those concerned in the resuscitation, especially those who had performed mouth to mouth respiration. The prophylactic regimen currently recommended by the Central Public Health Laboratory is rifampicin $600 \mathrm{mg}$ twice daily for two days, which has been shown to be effective in eliminating the carrier state. ${ }^{1}$ Since the incubation period of meningococcal disease is short, prophylaxis should be started as early as possible, and in this case this was made possible by the use of postmortem blood samples.

M J GLYNN

Charing Cross Hospital,
London W6 8RF

1 Devine LF, Johnson DP, Rhode SL, Hagerman CR, Pierce WE, Peckinpaugh RO. Rifampicin: effect of two-day treatment on the meningococcal carrie state and the relationship to the levels
saliva. Am $\mathcal{Y}$ Med Sci 1971;261:79-83.

\section{NHS theek hai?}

SIR,-The leading article by Dr John A Black highlights the difficulties facing the medical profession and ethnic minorities in Britain regarding the availability of medical care. We share Dr Black's view that there is a special need to educate Asians about the facilities available to them.

The West Midlands region has the highest recorded number of births in England and Wales to mothers born in the New Commonwealth and Pakistan. ${ }^{1}$ The problem of communication results in difficulty in advising these women on an appropriate method of analgesia for their labour. Last year we studied the use of analgesia for labour pain relief in Asian primigravidas. During the period of the study there were 213 births, 181 to Caucasian and 32 to Asian mothers. The two groups had a similar-duration of labour and no major differences in the course of their labours (see table). There were,

Details of analgesia in labour. Values are means (and SE)

\begin{tabular}{|c|c|c|c|}
\hline & $\underset{(n=181)}{\text { Caucasian }}$ & \multicolumn{2}{|c|}{$\underset{(\mathbf{n}=32)}{\text { Asian }}$} \\
\hline Duration of labour (h) & $9.9(0.5)$ & $12 \cdot 4$ & $(1 \cdot 6)$ \\
\hline $\begin{array}{l}\text { Time on labour ward betore } \\
\text { first analgesia (h) }\end{array}$ & $2.0(0.2)$ & & $(0 \cdot 2)$ \\
\hline $\begin{array}{l}\% \text { Or entire labour analgesia } \\
\text { given }\end{array}$ & $43 \cdot 0(5 \cdot 2)$ & $40 \cdot 0$ & $(\mathbf{1 1} \cdot \mathbf{2})$ \\
\hline $\begin{array}{l}\% \text { Given analgesia: } \\
\text { Pethidine } \\
\text { Epidural } \\
\text { Entonox } \\
\text { None }\end{array}$ & $\begin{array}{rr}43 & (3 \cdot 7) \\
39 & (3 \cdot 6) \\
10 & (2 \cdot 2) \\
7 & (1 \cdot 8)\end{array}$ & $\begin{array}{r}67 \\
22 \\
0 \\
9\end{array}$ & $\begin{array}{l}(8 \cdot 0) \\
(7 \cdot 3) \\
(5 \cdot 1)\end{array}$ \\
\hline
\end{tabular}

however, considerable differences in the methods of analgesia used. The differences between the Asians and the Caucasians were significant for the use of epidural analgesia $(p>0.05)$ and for intramuscular pethidine (p $>0.001$ )

The incidence of epidural use in Asians was half that in the Caucasians (see table). A greater use of epidurals for obstetric analgesia and for operative procedures has been advocated. ${ }^{2}$ Most of the Asian mothers received intramuscular pethidine, an inadequate analgesic in labour. ${ }^{3}$ Asian women with a poor knowledge of English are further disadvantaged since interpreters are readily available only during office hours.

If Asian mothers are to receive appropriate education interpreter services should be 
available throughout the day and printed information should be provided. The disparity that we have shown should diminish as today's Asian teenagers progress through the British education system and acquire language fluency.

J CARNIE
B KUMAR

Department of Anaesthetics,

East Birmingham Hospital,

East Birmingham Ho Hirmingham B9 5ST
Bits

1 Bailey PW, Howard FA. Epidural analgesia and forceps delivery. Laying a bogey. Aneesthesia 1983;37:282-5.

potential for regional block. Anaesthesia 1982;37:
porial 784-8.

3 Holdcroft A, Morgan M. An assessment of analgesic effect in labour of pethidine and entonox. Fournal of Obstetrics and Gynaecology of the British Commonwealth $1974 ; 81$ :603-7.

SIR,-The paper by $\operatorname{Dr} R$ Balarajan and others ( 3 November, $p$ 1185) and the leading article by Dr John A Black (8 December, p 1558) were interesting. I would like to comment in the light of recent observations of the Glasgow Asian community.

Asian names are a useful proxy for ethnic origin, but intermarriage and change of name sometimes make Asians unidentifiable by this method, while other people may be wrongly identified as Asian. The method requires validation to quantify the likely error. In a recent study (in preparation) I found that three out of 100 names thought to be Asian were not so. Dr Balarajan and others go one step further by identifying region of origin and Moslem religion on the basis of name. Have they validated their technique, and what is the magnitude of error ? I accept that Moslem names are distinct. In my study I found that grouping into Moslem and non-Moslem categories on the basis of names was correct in $94 \%$ of cases. In view of major migrations, particularly in Northern India, and the derivation of large numbers of Asians from East Africa, it is unlikely that region of origin can be predicted with accuracy.

Dr Balarajan and others have failed to explain the astonishing male to female mortality ratio of $2.5: 1$ that occurs in every age group including children. The male to female ratio in the general population is about $0.94: 1 .^{1}$ A partial explanation may lie in sex differences in the number of Asians seeking health care in Britain (it is documented that more money is spent on the health care of males in India). Furthermore, women may be more likely to return to the Indian subcontinent when ill. My observations of Asian society support both hypotheses. Clearly, further study, including analysis of mortality data controlled for time spent in the host country, is necessary to explore this issue.

Dr Black identifies the communication gap as a major problem in the health care of Asians. Both language and differing concepts of the cause of disease and therapy are important. Of $18 \%$ of my study group who perceived a language problem, most felt that a family interpreter was sufficient. Illiteracy in English usually means the same in the native language. Leaflets produced in Asian languages would be useful for only $17 \%$ of my study group and $20 \%$ of a group in the West Midlands. ${ }^{2}$

I found that most Asians I interviewed were satisfied with the care they received within the NHS. It would be wise to introduce some of Dr Black's suggestions while this level of good will is high.

Despite speaking fluent Punjabi and being conversant with Hindi it took me $\mathbf{4 8}$ hours to understand the title of the leading article. May I suggest that "theek" may be better phonetic spelling than "thik."

R BHOPAI

Department of Community Medicine, Ruchill Hospital,
Glasgow G20 9 NB

1 Central Statistical Office. Social trends No 15. London: HMSO, 1985 .

2 Aslam M, Davis SS, Fletcher R. Compliance in medication by Asian immigrants. Nursing Times
1979;75:931-2.

\section{What can we do about measles?}

SIR,-We enjoyed Dr N D Noah's leading article on measles immunisation (1 December, $p$ 1476). After four years of practice in the United States we have yet to encounter a case of measles. This situation is in stark contrast to our experience in a population of similar size in Britain. The difference is undoubtedly due to the very high levels of immunisation achieved here. These levels are in turn due to immunisation being virtually compulsory in Kansas. Children are not admitted to school unless they have stringent proof of immunisation or certification that immunisation is contraindicated on medical or religious grounds. Children are required by law to attend school-catch 22 operates.

Anyone drawing unfavourable comparisons between immunisation coverage in Britain and that in the United States has to allow for the differences between the two societies. The immunisation requirement for school is, by and large, accepted as normal here and few "civil liberty" issues are raised. Retaining a voluntary basis for the immunisation programme may confer a moral advantage to the British system but it also carries an intrinsic disadvantage.

\section{University of Kansas,}

School of Medicine,

ADRIAN WALIING ANNE WALLING

\section{The rules of the game}

SIR,-Dr Theo Schofield, attempting to explain how he "leaked" the Wilkin and Metcalfe study on list size and patient contact in general medical practice ( 5 January, p 68), accused Doctor newspaper of "gross misrepresentation" and of being "inaccurate" in reporting the Wessex faculty of the Royal College of General Practitioners symposium.

Significantly this sweeping and disparaging statement was not substantiated by any specific reference to how we were inaccurate or misrepresentative. Indeed, this would have been impossible since our report was entirely accurate and fairly represented. Furthermore, our early review of the Wilkin and Metcalfe study was subsequently verified by the publication of the results of that study.

It is curious that, having noted the presence of our reporter, Dr Schofield should have been surprised to see his meeting reported in Doctor, but he is inaccurate in stating that our reporter did not speak directly to any of the speakers afterwards. She did, in fact, contact Dr Bill Styles about the study and also talked to one of its authors, who described the results as "political dynamite." Dramatic words, perhaps, but they were not of our coining.

Far more serious is the inference in $\mathrm{Dr}$ Schofield's letter that Doctor is not a reputable journal. As Doctor, like other newspapers, is a composite of many things, I wonder if he extends his aspersions to include the many distinguished members of the medical profession who regularly contribute to its columns.

Dr Schofield's "conclusion" that organisers of academic meetings should exclude reporters of medical newspapers is more pompous than sinister. But if academics are not prepared to tolerate others seeing issues in a slightly different light from the way they themselves view them it would be a sad day for freedom of expression in this or any other country.

I appreciate Dr Schofield's concern that he has unwittingly been caught up in this particular issue, but to seek to blame Doctor as a means of extricating himself is grossly unfair.

\section{Barrie Freeman}

Doctor, Guildford, Surrey GU1 3AD

\section{"Tissue thyrotoxicosis"}

SIR,-We have read with interest the report by Dr P E Jennings and others (15 December, $p$ 1645), which suggests that in patients receiving thyroxine replacement therapy for primary hypothyroidism a raised serum thyroxine concentration may indicate tissue thyrotoxicosis and should prompt a reduction in the thyroxine dose. This statement has enormous implications for the management of such patients, many of whom show serum total thyroxine and free thyroxine concentrations above the normal range while receiving standard replacement doses $(100-200 \mu \mathrm{g})$ of thyroxine without showing any clinical features of thyrotoxicosis. ${ }^{2}$

The findings of Dr Jennings and others should be interpreted with caution. They describe 15 subjects in whom the serum free thyroxine concentration was above normal and in whom there was a statistically significant reduction in mean systolic time interval ratio when compared with a group of 200 normal subjects. Of the 15 subjects described, only nine fell outside the stated normal range for systolic time interval ratio. It is not clear whether the study subjects were matched according to age, sex, and other criteria to the group of 200 normal subjects or whether conditions for measurement of the systolic time interval ratio were standardised, since changes in this value can be induced by such factors as age, sex, position, the time of day of the recording, drug therapy, and the presence of cardiovascular disease. ${ }^{3-5}$

When seven patients were reinvestigated one month after a $50 \mu \mathrm{g}$ reduction in thyroxine dosage there was a significant increase in mean systolic time interval ratio $(0.25$ to 0.28$)$. Five out of seven of the subjects retested were outside the stated normal range before dose reduction, but the authors do not make it clear how many of the subjects were within the normal range after reduction. In a similar study from the same group the normal range for the systolic time interval ratio was considered to be 0.25 to 0.32 , using the same method of measurement. 6 The mean systolic time interval ratio of the seven reinvestigated subjects would therefore have been considered normal had the range quoted by the authors been that in their previous report. It is said that all seven subjects reinvestigated were clinically euthyroid and symptom free after reduction of their thyroxine dosage, but presumably the subjects were clinically euthyroid and symptom free before reduction.

We do not think that the authors have shown adequately the presence of "tissue thyrotoxicosis as assessed by cardiovascular ... responses," nor is it 